\title{
Research on the Incentive of Mathematics Teachers in Junior High School Based on the Sense of Efficacy*
}

\author{
Xiaofen Wang \\ Middle School Affiliated to Huaqiao University \\ Quanzhou, China 362021
}

\begin{abstract}
Based on the example of 231 junior high school mathematics teachers in Quanzhou, this paper studies the overall characteristics, characteristics and influencing factors of the teaching sense of efficacy of mathematics teachers in junior high schools. The result shows that: the teaching sense of efficacy of junior mathematics teachers and their scores in sub-items are all below the middle level. Through the regression analysis, they found that five factors of teachers' knowledge of disciplines and culture, teacher's teaching monitoring ability, teacher's ability to work together, school service and management, and students learning motivation as the important factors that affect teacher's teaching sense of efficacy. Finally, three aspects of the teacher's self-motivation and training motivation are proposed to improve teachers' teaching sense of efficacy.
\end{abstract}

Keywords-junior mathematics; sense of efficacy; teacher's incentives

\section{INTRODUCTION}

At present, junior high school mathematics teachers are faced with tremendous work pressure. Even many teachers are experiencing job burnout and lack of internal motivation. How schools effectively stimulate teachers and achieve organizational goals to become an important issue in school education management! This article takes the junior high school mathematics teacher's sense of teaching sense of efficacy as the starting point and discusses the motivation of junior middle school mathematics teachers. The junior high school math teacher's teaching sense of efficacy refers to whether junior high school mathematics teachers have the right understanding and reasonable value orientation of the junior high school mathematics education, the correct understanding of the school organization's educational goals and concepts, and whether they are willing or able to perform junior mathematics teaching tasks. Is it possible to achieve the goals and concepts of the school organization's educating people and their perceptions, inferences, and levels of confidence in the face of these consequences?

\section{OBJECTS AND METHODS}

Based on Yu Guoliang, Xin Tao, Shen Jiliang (1995) [1], the measurement scale of this article, combining the relevant theory of teacher's teaching sense of efficacy, the features of

*This paper is the periodical research results of university-level fund project of Huaqiao University in 2017 Research on Organizational Human Resources Incentive Based on Sense of Efficacy (Approval No. 17HJY10). junior middle school mathematics and the uniqueness of junior middle school teaching, in the context of the reform of the new mathematics curriculum that has been vigorously promoted in the field of basic education, referring to relevant literature materials, combining with experts' advice, from the perspective of the new mathematics curriculum reform, the teaching sense of efficacy of junior middle school mathematics teachers is measured by their professional knowledge and teaching skills, humanistic quality, emotional attitude and values. There are three parts of the scale, which are the basic demographic information of the respondents, the teaching sense of efficacy rating scale of junior middle school mathematics teachers, and the influence factors of the teaching sense of efficacy of mathematics teachers. Among them, there are 36 questions in Scale of teaching sense of efficacy for junior mathematics teachers, and 10 of them are general teaching sense of efficacy, 17 individual teaching sense of efficacy; 9 mathematics measurement of teaching sense of efficacy; the options for each question range from complete disapproval to full approval of 5 options, respectively corresponding to a positive score of $1-5$ points. In order to improve the effectiveness of the questionnaire, 10 reverse questions are set, that is, adopting reverse score among the question $12,15,18,20,22,27,29,31,33$, and 35. After analysis, the results show that the questionnaires for teaching sense of efficacy of junior middle school mathematics teachers have good reliability and validity, and fully meet the requirements of statistical analysis. Taking Quanzhou mathematics teachers from four districts, three cities and four counties as the survey objects, according to the principle of random sampling, 248 questionnaires were distributed and 240 were recovered. According to the completeness and validity of the questionnaire, 9 invalid questionnaires were deleted, and 231 valid questionnaires were retained. The recovery rate of the questionnaire was $96.8 \%$, and the effective questionnaire rate was $96.25 \%$

\section{RESULTS AND ANALYSIS}

\section{A. General Situation of Teachers' Sense of Efficacy}

From "Table I", the average score of teaching sense of efficacy of junior high school mathematics teachers in Quanzhou city was 81 points $<108$ points (Thirty-six questions in the scale were scored with a 5-point score of $1-5$, with a minimum score of 36 and a maximum score of 180, with an intermediate threshold of 108.) The average score of 
Quanzhou mathematics teachers' teaching efficacy in the three dimensions are respectively $28.73,34.22$, and 18 , which are respectively lower than the corresponding intermediate threshold of 30, 51 and 27. Thus it can be seen that the teaching sense of efficacy of junior high mathematics teachers in Quanzhou and their scores in sub-items are below the medium level. From the perspective of teachers' teaching sense of efficacy, the development of junior high school mathematics teachers in Quanzhou needs to be strengthened in terms of teachers' knowledge and concepts, teachers' independent development, teacher incentives, and teachers' positive experience.

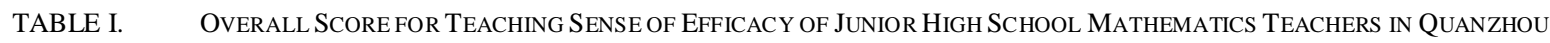

\begin{tabular}{|l|l|l|l|l|l|l|}
\hline & N & Minimum & Maximum & \multicolumn{1}{c|}{$\begin{array}{c}\text { Average } \\
\text { Number }\end{array}$} & $\begin{array}{c}\text { Standard } \\
\text { Deviation }\end{array}$ & $\begin{array}{c}\text { Intermediate } \\
\text { Threshold }\end{array}$ \\
\hline General education sense of efficacy & 231 & 12 & 45 & 28.73 & 6.62 & 30 \\
\hline Individual teaching sense of efficacy & 231 & 18 & 53 & 34.22 & 7.68 & 51 \\
\hline Teaching sense of efficacy for mathematics & 231 & 9 & 32 & 18.0 & 4.90 & 27 \\
\hline $\begin{array}{l}\text { Teaching sense of efficacy for mathematics } \\
\text { teachers (total) }\end{array}$ & 231 & 48 & 120 & 81.0 & 12.2 & 108 \\
\hline
\end{tabular}

B. The Teaching Sense of Efficacy of Junior High School Mathematics Teachers in Different Types of School

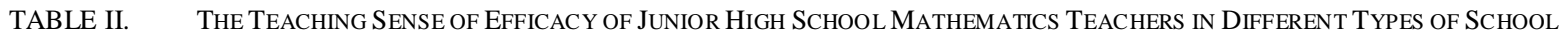

\begin{tabular}{|c|c|c|c|c|c|c|}
\hline \multicolumn{7}{|c|}{ Ordinary Junior High School （N=202） Demonstration Junior High School （N=29） } \\
\hline Description & $\begin{array}{l}\text { Average } \\
\text { number }\end{array}$ & $\begin{array}{c}\text { Standard } \\
\text { deviation }\end{array}$ & $\begin{array}{l}\text { Average } \\
\text { number }\end{array}$ & $\begin{array}{c}\text { Standard } \\
\text { deviation }\end{array}$ & $T$ & \\
\hline General education sense of efficacy & 27.48 & 5.82 & 28.90 & 6.72 & 1.07 & 0.28 \\
\hline Individual teaching sense of efficacy & 33.03 & 9.07 & 36.40 & 7.47 & 0.89 & 0.37 \\
\hline Teaching sense of efficacy for mathematics & 17.44 & 6.14 & 22.04 & 4.71 & 0.50 & $0.01 *$ \\
\hline Teaching sense of efficacy for mathematics teachers & 77.96 & 13.52 & 87.35 & 11.93 & 0.50 & $0.01 *$ \\
\hline
\end{tabular}

It can be seen from the analysis by using the independent sample T: the average number of teaching efficacy of junior high school mathematics teachers in demonstration schools is higher than that of ordinary junior high school teachers. There is no significant difference in general education efficacy and individual teaching efficacy. However, there is a significant difference in mathematics teaching sense of efficacy and mathematics teachers' teaching sense of efficacy at 0.01 level. The score of teaching sense of efficacy of junior high school mathematics teachers from demonstration schools is higher than that of ordinary junior high schools. In addition to the influence of sample size, it is even more important that teachers from demonstration schools have high levels of confidence in education and teaching, full of confidence in the teaching skills of mathematics and its own strength.

\section{Analysis on the Difference in Teachers' Teaching Sense of Efficacy in Different Genders}

TABLE III. Group Statistics of Teaching EFFicacy of Junior High School Mathematics Teachers of DifFERENT Genders

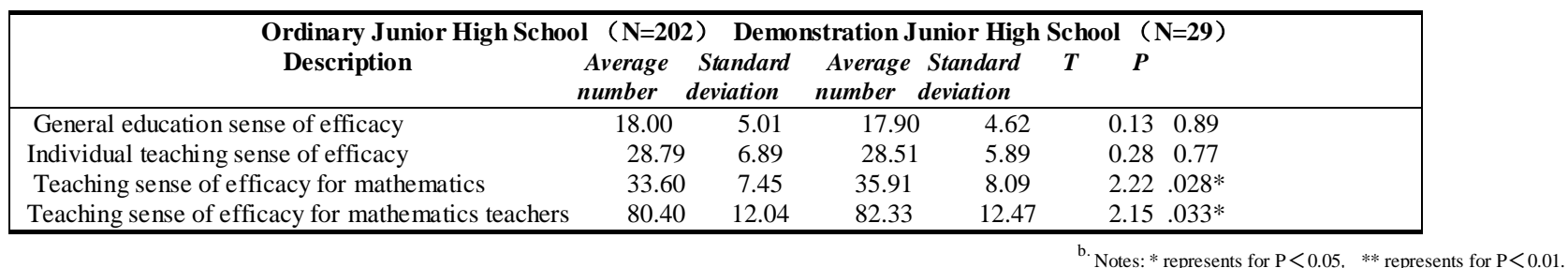

By using the independent sample $\mathrm{T}$ test, this paper analyzes the present situation of teaching sense of efficacy of junior high school mathematics teachers in Quanzhou city of different genders: in terms of general education efficacy, the average number of male teachers is 18.00 and the average number of female teachers is 17.90 . The performance of the two teachers is basically the same. In terms of individual teaching sense of efficacy, the performance of both is basically the same. The score of male teachers is slightly higher than that of female teachers. However, there is significant difference in the average number of male and female teachers in mathematics teaching sense of efficacy and mathematics teachers' teaching sense of efficacy. Specifically, in terms of mathematics teaching sense of efficacy, the average number of female teachers is 35.91 , which is higher than 33.6 for male teachers; in mathematics teachers' sense of teaching efficacy, the average number of female teachers is 82.33, which is higher than that of male teachers. In summary, the influence of gender on mathematics teachers' teaching sense of efficacy is obvious. 
D. Analysis of Differences in Teachers' Teaching Sense of Efficacy on Different Professional Titles

Professional title is an important embodiment of teachers' work ability, level of learning, and professional skills. This article uses the single-factor analysis of variance for the primary, intermediate, and senior professional titles in the sample to calculate the average number of the teaching sense of efficacy of junior mathematics teachers in different titles (see in "Table IV"), so that to vary the difference of mathematics teachers' teaching sense of efficacy among different professional titles.

TABLE IV. ANALYSIS OF DIFFERENCES IN TEACHERS' TEACHING EFFICACY ON DIFFERENT PROFESSIONAL TITLES

\begin{tabular}{|c|c|c|c|c|c|}
\hline \multirow{4}{*}{ Primary professional title } & \multicolumn{2}{|c|}{ General Education } & Individual Teaching & Mathe matics Teaching & \multirow[t]{2}{*}{ Mathematics } \\
\hline & \multirow{2}{*}{\multicolumn{2}{|c|}{ Sense of Efficacy }} & \multirow{2}{*}{$\begin{array}{l}\text { Teachers } \\
\text { Sense of Efficacy }\end{array}$} & \multirow[b]{2}{*}{ Sense of Efficacy } & \\
\hline & & & & & Sense of Efficacy \\
\hline & Mean value & 27.39 & 31.08 & 15.57 & 74.04 \\
\hline $\mathrm{N}=33$ & Standard deviation & 6.31 & 8.14 & 4.32 & 11.97 \\
\hline Intermediate professional title & Mean value & 28.29 & 34.22 & 18.51 & 81.02 \\
\hline $\mathrm{N}=141$ & Standard deviation & 6.60 & 7.38 & 5.27 & 12.09 \\
\hline Senior professional title & Mean value & 30.56 & 35.25 & 18.81 & 84.62 \\
\hline $\mathrm{N}=57$ & Standard deviation & 6.61 & 7.40 & 4.74 & 11.86 \\
\hline $\mathrm{F}$ value & & 3.21 & 6.63 & 9.77 & 3.70 \\
\hline $\mathrm{P}$ value & & $.042 *$ & $.002 * *$ & $.000 * *$ & $.026 *$ \\
\hline
\end{tabular}

Notes: * represents for $\mathrm{P}<0.05$, *** represents for $\mathrm{P}<0.01$

According to the results of the single-factor analysis of variance in Table 4, the general education sense of efficacy and individual teaching sense of efficacy of junior high school mathematics teachers with primary, intermediate, and senior professional titles are significantly different in the statistical significance at 0.05 level; there is a significant difference in statistical significance between mathematics teaching sense of efficacy and mathematics teachers' teaching sense of efficacy at 0.01 level. Junior high school mathematics teachers with primary and junior professional titles, their general education sense of efficacy, individual teaching sense of efficacy, mathematics teaching sense of efficacy, and mathematics teacher teaching sense of efficacy all show the trend of increasing in synchronization with teachers' titles.

\section{E. Analysis of Differences in Teachers' Teaching Sense of Efficacy in Different Positions}

TABLE V. ANALysis OF DifFERENCES IN TEACHERS' TEACHING SENSE OF EFFICACY IN DIFFERENT POSITIONS

\begin{tabular}{|c|c|c|c|c|c|c|}
\hline \multicolumn{3}{|c|}{ ers with Administrative Positi } & \multirow{2}{*}{$\begin{array}{l}(\mathrm{N}=146 \\
\text { Average } \\
\text { number }\end{array}$} & \multicolumn{3}{|c|}{ Full-Time Teacher $(\mathrm{N}=85)$} \\
\hline Description & $\begin{array}{l}\text { Average } \\
\text { number }\end{array}$ & $\begin{array}{l}\text { Standard } \\
\text { deviation }\end{array}$ & & $\begin{array}{l}\text { Standard } \\
\text { deviation }\end{array}$ & $T$ & $P$ \\
\hline General education sense of efficacy & 28.96 & 6.60 & 26.30 & 6.30 & 2.07 & $0.03 *$ \\
\hline Individual teaching sense of efficacy & 34.87 & 7.31 & 33.21 & 8.31 & 2.14 & $0.03 *$ \\
\hline Teaching sense of efficacy for mathematics & 19.23 & 4.94 & 17.77 & 4.84 & 3.74 & $0.00 * *$ \\
\hline Teaching sense of efficacy for mathematics teachers & 83.06 & 11.89 & 77.28 & 11.93 & 5.15 & $0.00 * *$ \\
\hline
\end{tabular}

In order to examine the differences in the teaching efficacy of mathematics teachers in different positions, this article divides teachers into two groups: head teachers/ teacher with administrative positions and full-time teachers, adopts independent sample $\mathrm{T}$ test to respectively calculate the average number of junior high school mathematics teachers' teaching sense of efficacy in different positions (see in "Table V"). According to "Table V", it can be known that there is a significant difference in the sense of teaching sense of efficacy between head teachers/teachers with administrative positions and full-time teachers in the general education sense of efficacy, individual teaching sense of efficacy, mathematics teaching sense of efficacy and mathematics teachers' teaching sense of efficacy. From the view of average number, the scores of professional teachers who served as head teachers on the four are higher than those of full-time teachers.

\section{F. Regression Analysis on the Factors of Teachers' Teaching Sense of Efficacy}

Taking mathematics teachers' teaching efficacy as the dependent variable, regression analysis is based on teachers' subject knowledge and culture, teaching monitoring ability, ability to work, school service and management, and student learning motivation. The results show that all five variables have entered the regression equation. These five variables can explain the $86 \%$ variation in the teaching sense of efficacy of mathematics teachers in junior high schools (with R2 of 0.86). The significance test of the variance analysis of the regression equation shows that the regression equation has reached a significant level $(\mathrm{F}=275.852, \mathrm{P}<0.01)$, which can be seen that it is reliable and statistically significant to use these independent variables to predict the teaching sense of efficacy of mathematics teachers. The regression equation can be expressed as: junior high school mathematics teachers' teaching sense of efficacy $=18.145+1.969^{*}$ teachers' teaching monitoring ability $+1.682 *$ students learning motivation $+1.440 *$ teachers' knowledge of disciplines and culture $+1.281^{*}$ teachers' ability to work together+1.148* school service and management. 


\section{CONCLUSION AND SUGGESTIONS}

Based on the example of 231 junior high school mathematics teachers in Quanzhou, this paper studies the overall characteristics, characteristics and influencing factors of the teaching efficacy of mathematics teachers in junior middle schools. The result shows that: the teaching sense of efficacy of junior mathematics teachers and their scores in subitems are all below the middle level. Through the regression analysis, they found that five factors of teachers' knowledge of disciplines and culture, teacher's teaching monitoring ability, teacher's ability to work together, school service and management, and students learning motivation as the important factors that affect teacher's teaching sense of efficacy.

In the aspect of teachers' independent incentives, the observation, recording, discussion and exchange among companions in peer-to-peer interactions, interactive dialogues make up for deficiencies in teaching and help improve teaching standards [2], which can be seen that it is possible to self-motivation and promote professional growth of teachers by mutual cooperation through companies. In addition, mathematics is a particularly reflective discipline. As educators, in the face of educated people's need and desire for knowledge, teachers should respond to the demands of students and parents for receiving good education. In line with the "student-centered" philosophy, teachers shall do a good job in education and teaching, strengthen education narrative research, enhance teachers' teaching competencies, be diligent in reflection and study, and consciously promote the promotion of professionalism.

In terms of training incentives, the improvement of teachers' knowledge structure, the development of teachers' professionalism and the improvement of their quality are of great significance in improving teachers' sense of teaching efficacy. But the well-developed in-service teacher training is an important prerequisite for the scientific and rational training of new teachers. [3] The survey found that more than $78.86 \%$ of teachers believe that mathematics teachers' new curriculum training is helpful for mathematics teaching. Therefore, it is necessary to strengthen professional training for teachers to meet the needs of teachers' growth and development. Through training, teachers can master scientific attribution methods, enhance their sense of internal autonomy, and develop career planning to improve teachers' self-sense of efficacy.

\section{REFERENCES}

[1] Yu Guoliang, Xin Tao, Shen Jiliang. Teachers' teaching sense of efficacy: study on structure and factors [J]. Journal of Psychiatry, 1995, 27 (2): 159-166 俞国良, 辛涛, 申继亮. 教师教学效能感:结构与影响因 素的研究[J].心理学报,1995,27 (2):159-166

[2] Linik, J.R. Surviving the Crossfire: Walla.s Mentoring Program Helps Neophytes Triumph over the Challenges of Teaching[J].Northwest Education, 2001, 7(2):30235

[3] Li Ying. Study on strategies of improving high school teachers' teaching sense of efficacy [J]. Journal of Changchun Normal College (Humanities and Social Science Edition), 2010, 7 李芗.关于高校教师 教学效能感提升策略的研究 $[\mathrm{J}]$. 长春师范学院学报 (人文社会科学 版), 2010, 7 